\title{
A simple pendulum experiment to explain resonance and absorption
}

\section{W. Holtz}

To cite this article: W. Holtz (1888) A simple pendulum experiment to explain resonance and absorption, Philosophical Magazine Series 5, 26:161, 396-396, DOI: 10.1080/14786448808628284

To link to this article: http://dx.doi.org/10.1080/14786448808628284

曲 Published online: 29 Apr 2009.

Submit your article to this journal $₫$

Џll Article views: 2

Q View related articles $\sqsubset$ 
from a syrupy consistence almost to the state of solid, this difference is scarcely $1^{\circ}$.

In order to confirm the part which we have ascribed to the ether we have made experiments with the following solvents. We have obtained the following results :- -

Temperature

observed.

\begin{tabular}{|c|c|}
\hline Chloride of methyle & -82 \\
\hline Sulphurous acid.... & -82 \\
\hline Acetate of amyle ........ & -7 \\
\hline Terchloride of phosphorus & -76 \\
\hline Bisulphide of carbon . . . . . & -74 \\
\hline Absolute alcohol $\ldots$. & -72 \\
\hline Chloride of ethylene ....... & -6 \\
\hline
\end{tabular}

With the last three liquids, and especially with chloride of ethylene, the solubility of carbonic snow is manifestly less than the otbers. These also are the liquids which produce least cooling.

By producing a vacuum over these liquids we can, as Faraday has shown, materially reduce the temperature, even below $-100^{\circ}$. With chloride of methyle and sulphurous acid it happens that this temperature in a vacuum is sufficiently low to solidify the solvent. All the mass then becomes solid, and from this point the temperature remains almost stationary.

The lowest temperature we have obtained under these conditions is with chloride of methyle. Solidification only takes place at about $-106^{\circ}$.

With cbloroform, whose freezing-point is below that of carbonic acid, the action of the vacuum is not needed to produce this effect. Carbonic snow gradually added to the liquid dissolves at first with disengagement of carbonic acid. When the temperature has sunk to $-77^{\circ}$ this ebullition ceases suddenly, and the whole mass solidifies. There is thus a freezing mixture which congeals under the influence of its own cooling.-Journal de Physique, September 1888.

\section{A SIMPLE PENDULUM EXPERIMENT TO EXPLAIN RESONANCE AND ABSORPTION. BY W. HOLTZ.}

A caoutchouc tube is stretched between two door-posts by means of packthread attached to the ends, and nails. If two string pendulums are bung over this by means of hooks equidistant from the ends at about $\frac{1}{6}$ of the width of the door, and if an impulse be given to one, the other is set in oscillations which jncrease as the others slacken. When the original one has come to rest the phenomenon is inverted. If the pendulums are unequal the second begins to vibrate indeed, but the vibrations do not continuously increase.-Beiblätter der Physik, No. 7, 1888. 